\title{
Discurso do Senador Públio de Mello
}

\begin{abstract}
Justas foram as homenagens que o Senado, através da palavia do ilustre Senador Públio DE Mello, prestou à memória do $D r$. Urbano Santos da Costa Araújo, ao ensejo do primeiro centenário de seu nascimento.

Vice-Presidente da República nos governos Venceslau Braz e Artur Bernardes, Governador, Senador e Deputado em várias legislaturas, o Dr. Urbano Santos DA Costa Araújo marcou a vida politica do seu Estado Natal, o Maranhão, bem como a do país, com uma administração e uma atividade politica devotadas ao bem e à grandeza da causa pública.
\end{abstract}

Sua cultura juridica, seus abalizados pareceres de financista e sua inquebrantável correção moral de atitudes valeram-lhe o respeito e a admiração de seus contemporâneos.

Numa hora em que nem sempre essa virtudes estão presentes na atuação ou na vocação de muitos dos nossos politicos, as homenagens do Senado revestem-se, por isso mesmo. de especial significação.

Associando-nos a essas homenagens, transcrevemos a integra do discurso proferido pelo Senador Públio de Mello, digno representante do Maranhão na nossa Câmara Alta.

Senhor Presidente, Senhores Senadores, interpretando o pensamento da Bancada do Maranhão no Senado da República, venho à tribuna para prestar o preito de nossas homenagens à memória do preclaro e saudoso estadista que fôra o Dr. Urbano Santos da Costa Araújo, ao ensejo do primeiro centenário de seu nascimento, a verificar-se no dia 3 de fevereiro.

Antecipamos para hoje, essa comemoração, pela circunstância do próximo encerramento da presente sessão legislativa.

O Maranhão cumpre neste momento, o patriótico dever de exalçar perante a Nação, o nome e os feitos do patrício ilustre que tão alto soube manter o passado glorioso de nossa terra, conquistando com inteligência e saber as mais destacadas posições, assim no Estado, como na República.

Pode-se dizer que a sua carreira pública se desdobrou numa série ininterrupta de magníficos triunfos. Nenhum maranhense atingiu, como êle os mais elevados postos da administração e da política. 
Na cidade de Guimarães da antiga Província, nasceu Urbano Santos no dia 3 de fevereiro de 1859 , descendendo de importante familia da localidade.

Feito o curso de humanidades em S. Luís, seguiu para Pernambuco, formando-se, em 1882, na tradicional Faculdade de Direito de Recife.

A passagem do jovem maranhense pela famosa Academia fôra assinalada pelo brilho de sua inteligência e notória dedicação aos estudos. Filiou-se à corrente dos acadêmicos que, ardorosos e entusiastas, bebiam as sábias lições de ToBIAS BARRETO, o emérito evangelizador da cultura jurídica e filosófica assimilada nas obras dos escritores alemães.

Tivera por companheiros de turma, entre outros, Clovis Bevilaqua, Benedito Pereira Leite, Filinto Justiniano Ferreira Bastos, José Xavier Carvalho de Mendonça, Alfredo Raposo Barradas, Manoel Lopes Da Cunha e Torquato Coelho DE Sousa, nomes de relêvo do :nundo jurídico, político e da magistratura do Brasil e do Estado.

O Sr. PRESIDENTE (Fazendo soar os timpanos) - Permito-me lembrar ao nobre orador que a hora do expediente está por findar.

O Sr. FILINTO MüLleR (Pela ordem) - Sr. Presidente, requeiro a V. Ex ${ }^{a}$ consulte a Casa sôbre se consente na prorrogação da hora do expediente, a fim de que o nobre Senador Públio de Mello possa concluir sua brilhante oração.

O Sr. PRESIDENIE - O Senado acaba de ouvir o requerimento do nobre Senador FILINTO MüLler. (Pausa)

Os Srs. Senadores que o aprovam queiram conservar-se sentados.

Está aprovado. Continua com a palavra o nobre Senador PúBlio de Mello.

Agradeço, ao nobre líder da maioria, o gesto que teve para que seu humilde colega possa concluir esta pálida oração. (Não apoiados).

Regressando ao Maranhão, coube-lhe, de início, desempenhar função do Ministério Público na Comarca Sertaneja de Mirador, a fim de acompanhar processo de ruidoso crime que ali se verificou.

Abriram-se-lhe, depois, as portas da magistratura. Fôra então nomeado Juiz de Direito da Comarca de S. Bento, da qual se transferiu mais tarde, para a de Rosário, onde permaneceu por mais tempo e adquiriu afeições que jamais esqueceu. Mas, não era essa, $\mathrm{Sr}$. Presidente, a profissão que melhor se coadunava com a atividade de seu espírito. Cedo, despiu a toga de magistrado que soube ser com integridade, para dedicar-se às lides da política, dentro das quais, se fixou até o final da existência.

Conhecendo-lhe os méritos intelectuais e as simpatias que desfrutava, com evidente prestígio para seu nome, o Partido chefiado pelo Dr. Benedrto LEITE, que representava a maior forrça politica do Estado, o indicava para uma das cadeiras da representação maranhense na Câmara Federal. No mesmo ano, o Dr. Urbano Santos era eleito Governador do Estado, dada a confiança que nêle depositava o Dr. BenEDITo LEITE, seu amigo de infância e dos tempos escolares e acadêmicos. 
O Dr. UnBANo, porém, por conveniência própria, preferiu continuar na Câmara. Como Deputado, mostrou-se diligente e operoso, distinguindo-se nos debates em que tomou parte e nos pareceres que proferiu nas comissões.

Finda a legislatura, ascendeu à Câmara Alta do país, como Senador da República, representante do nosso Estado.

Foi na Casa de Rui Barbosa, na convivência com os próceres da política Nacional, a cuja frente se colocava o General Pinheiro Machado, com o extraordinário prestígio ainda não ultrapassado, que o Dr. URBANo SANTOS conquistou a maior projeção, atraindo a consideração e o respeito de seus pares que nêle reconheceram o homem de Estado com os predicados necessários para exercer as mais elevadas posições.

No quatriênio de 1914-1918, era Vice-Presidente da República na chapa com o Dr. Venceslau Braz. Neste caráter, o Dr. Urbano Santos assumiu a Presidência da República, na ausência do Presidente Venceslau Braz. Terminado o mandato Vice-Presidencial, o Dr. UnBano voltou ao Estado, eleito, outra vez, seu Governador, quando introduziu importantes melhoramentos na vida administrativa do Estado, especialmente no setor das finanças, da instrução e da magistratura, cujos vencimentos estabeleceu em melhores bases, atenuando, dêste modo, a difícil situação em que se encontravam os magistrados maranhenses.

Pouco tempo se demorou à testa do Govêrno do Maranhão, por ter sido convidado pelo Presidente Rodrigues Alves, para ocupar a pasta da Justiça, o que ocorreu na presidência interna do Dr. Delfim Moreira.

Deixando o Ministério da Justiça, com a posse do Dr. Eprtácio Pessoa na Presidência da República, o Dr. Urbano Santos tornou ao Govêrno, para concluir a seu mandato. Mais uma vez, se constatou a projeção do emınente governador do Maranhão, no cenário da politica brasileira.

Fôra novamente eleito Vice-Presidente da República, em 1922, no quatriênio do Presidente Artur Bernardes. Desta vez, porém, Deus não lhe permitiu assumir o alto pôsto, por haver falecido a sete de maio dêsse ano, a bordo do navio "Afonso Pena», em viagem de S. Luis, para esta capital.

Cumpre ressaltar que, no decurso de sua longa carreira pública, o Dr. URBANo Santos soube impor-se aos seus concidadãos, pela firmeza de seu caráter e pela linha inamolgável de sua conduta, qualidades que the granjearam o incontestável prestigio que desfrutava nas esferas da politica e da administração.

Sobressaiu-se no Congresso Nacional, como reputado financista, deixando eruditos pareceres reveladores de sua grande capacidade no dominio da ciência das finanças.

Há na vida do Dr. Unbano Santos episódios que bem definem os escrúpulos de uma consciência reta.

Quando foi convidado pelo Dr. Rodrigues Alves, para Ministro da Justiça, ao chegar ao Rio, já encontrou o Presidente acamado da insidiosa moléstia, da qual veio a falecer. Pediram-lhe os amigos que não assumisse a pasta, a fim de se não incompatibilizar para candidato à Presidência da 
República. Respondeu-lhes o Dr. Urbano: «Estava no govêrno do meu Estado, de onde êste homem me mandou chamar para fazer parte de seu govêrno, distinguindo-me com a sua confiança». "Ao chegar aqui, vou jogar com a sua vida, para ser Presidente da República?» «Assumo a pasta da Justiça amanhã».

No dia seguinte, assumira a pasta, ficando dêste modo, incompatibilizado para concorrer à eleição Presidencial, com a prévia certeza da vitória. Pouco depois, falecia o Presidente Rodrigues Alves, e o indicado para suceder-lhe foi o Dr. EPITÁcIO PESSOA, em reunião política realizada no escritório do próprio Dr. URBANO.

Certa vez, ainda deputado, determinado cavalheiro, interessado pela aprovação de um projeto na Câmara, procurou o politico maranhense e disse-lhe: «Sei que o Sr. não votaria ao meu favor, mas ofereço-lhe uma elevada quantia, para que não compareça à Câmara, no dia da votação». Respondeu-lhe o Dr. URBANO: «Vou à Câmara, sem falta, para votar contra o Sr.».

Esforçara-se por manter a concórdia e a harmonia entre os partidos, visando a tranqüilidade do país.

Apontado para Vice-Presidente da República na chapa ArTur BERNARDES, nas proximidades do pleito, o Dr. URBAno SANTOS recebeu telegrama do Presidente EpITÁcio PESSOA, inquirindo se concordava com a retirada de sua candidatura, visto que os Drs. Artur Bernardes, Nilo PeÇANHA e JoAquim SEABRA manifestaram-se por uma chapa de conciliação.

Com desprendimento e renúncia, respondeu o Dr. Urbano Santos, declarando que estava de acôrdo com tôda a solução que fôsse para a paz da Nação.

Dias depois, o Presidente ExITÁcio PEssoA, em outro telegrama, comunicava-lhe que S. Paulo, pelo' seu Presidente Washington Luiz, não aceitava outra chapa, que não fôsse Artur Bernardes-Urbano Santos. Estava, assim, definitivamente assentada, pela segunda vez, a candidatura do Dr. Uribano Santos à Vice-Presidência da República .

Refutando increpações sôbre a sua orientação na chefia do partido dominante no Maranhão, assim se manifestou:

«É certo que trabalhei para reunir os nossos partidos. Depois da confusão dêles, da qual não fui causa, verifiquei que os não separava qualquer differença de idéias, que não havia principios que os dividissem, senão :ivalidades entre pessoas determinadas, umas das outras, por motivos sem a meror valia. Então afigurou-se-me ser possivel, esquecidas essas rivalidades, a união de todos os maranhenses ao redor de um objetivo comum: - progresso da Maranhão».

O Dr. URbano Santos também se notabilizou na advocacia exercida no fôro desta capital, onde se tornou provecto profissional, chegando a possuir movimentado escritório.

Inspirava tal confiança aos clientes, que um dêles propôs-lhe deixasse a politica e a sua casa se responsabilizaria pelos seus subsidios. O Dr. URBANO SANTOS resolveu continuar na politica e fechou o escritório: 
Clovis Bevilaqua a êle se referiu com as seguintes palavras: «Bela inteligência e boa cultura, tanto filosófica quanto juridica». Depois de enumerar os cargos que ocupou, disse o fulgurante mestre de Direito: «Além de político, foi notável advogado nos auditórios do Distrito Federal».

Eis aí, Sr. Presidente, em breves traços, a figura inesquecível de um homem de cultura aprimorada na sua biblioteca de mais de 8.000 volumes, dotado de elevado espirito público, de um patriota exemplar, carregado de serviços à sua Pátria, digno de ser imitado pelas gerações de todos os tempos.

Sr. Presidente, por tudo isso, por tôdas estas pálidas considerações que ai ficam, é sobremodo justa a homenagem do nosso Estado, através de sua bancada no Senado, à memória do inolvidável brasileiro, ao transcorrer o primeiro centenário de seu nascimento.

Certamente, Sr. Presidente, esta singela homenagem merecerá o apoio do Senado que o Dr. Urbano Santos presidiu como Vice-Presidente da República, porque, nesta casa do Parlamento, êle serviu aos mais altos intcrêsses do Brasil e da República, com tôda dignidade e patriotismo. (Muito bem, muito bem. Palmas.).

Durante o discurso do Sr. Públio de Mello, o Sr. Apollonio Sales deixa a Presidência, assumindo-a o Sr. Vitorino Freire.

O Sr. PRESIDENTE - A mesa associa-se à homenagem prestada pelo nobre Senador PúBlio DE MELlo, em nome da representação maranhense, ao Dr. Urbano Santos da Costa Araújo, pelo centenário do seu nascimento.

Exerceu o eminente homem de Estado quase todos os postos da vida pública, no âmbito estadual e federal. Vice-Presidente, ocupou a Presidência da República e duas vêzes presidiu a essa casa, com inteligência e honradez. (Palmas.) 